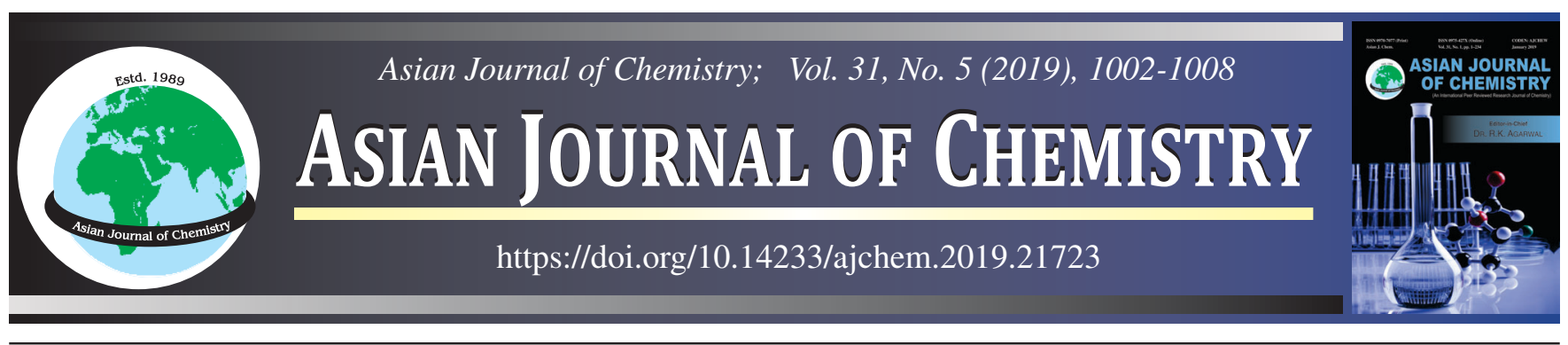

\title{
Development of Simple and Robust RP-HPLC Method for Determination of Everolimus and its Impurities in Oral Solid Dosage Form
}

\author{
Somana Siva Prasad ${ }^{\circledR}$, G.V. Krishna Mohan ${ }^{*}{ }^{\circledR}$ and A. Naga BabU ${ }^{\circledR}$
}

Department of Chemistry, Koneru Lakshmaiah Education Foundation, Vaddeswaram-522502, India

*Corresponding author: E-mail: drkrishnamohangv@kluniversity.in

Received: 25 September 2018;

Accepted: 29 November 2018;

Published online: 28 March 2019;

AJC-19320

\begin{abstract}
A novel reversed-phase high performance liquid chromatographic (HPLC) technique for the determination of everolimus (Isomer-B) and its impurities in the tablet dosage form has been optimized using analytical quality by design (QbD) approach. All the compounds are monitored with the photodiode array (PDA) detector at $280 \mathrm{~nm}$ and the parameters namely; precision, accuracy, specificity, stability, linearity, limit of quantitation (LOQ) and limit of detection (LOD) are evaluated. The quantitation limits of IMP-A, IMP-B, IMP-C, IMPD, IMP-E, Sirolimus and TGR are found to be $0.08,0.08,0.10,0.10,0.10,0.08$ and 0.08 , respectively. Recovery studies from 0.9 mg/L to $9.0 \mathrm{mg} / \mathrm{L}$ are performed for all impurities and the values were obtained between $85-110 \%$. Injection volume and test concentrations have been optimized to achieve LOQ values under the reporting threshold. The whole technique is developed and validated as per International Council for Harmonization (ICH) guidelines. The proposed method is robust, sensitive, rapid and successful and helpful in the regions where regulatory agencies recommend HPLC analytical method.
\end{abstract}

Key

Keywords: Analytical quality by design, HPLC-PDA, Experimental design, Everolimus, Validation.

\section{INTRODUCTION}

Everolimus is a semi-synthetic 40-O-(2-hydroxyethyl) derivative of sirolimus, which is originally isolated from Streptomyces hygroscopicus. It is used as an anticancer medicine for the advanced kidney cancer and prevents the organ transplantation rejection. The molecular formula and molecular weight of everolimus are $\mathrm{C}_{53} \mathrm{H}_{83} \mathrm{NO}_{14}$ and $958.2 \mathrm{~g} / \mathrm{mol}$, respectively. Everolimus has many advantages over calcineurin inhibitors and an effective immunosuppressant with good tolerance, cancer preclusion (inhibits cell propagation) and preventive effects on cardiovascular morbidity. Within the distinctive concentration range of $1-15 \mu \mathrm{g} / \mathrm{L}$, the everolimus is potent and generally it coupled with the mammalian target of rapamycin protein (mTOR) for rapid and sensitive inhabitation [1]. Further, it is suggested for the adult patient's treatment to prevent the proliferation of B-cells and T-cells with progressive neuroendocrine tumours of pancreatic origin [2]. It has been approved in the USA and the EU for the prophylaxis of organ refusal in patients who are accepting liver transplantation in combination with steroids and tacrolimus [3]. Hepatocellular carcinoma
(HCC) is the universal liver tumour, which causes the deaths related to cancer [4]. However, the everolimus-based immune liver transplantation has been well benefitted to the hepatocellular carcinoma patients [5]. In the early phase after liver transplantation, everolimus is proven to be beneficial to the renal dysfunction patients in combination with calcineurin inhibitors [6].

For the estimation of solo everolimus, some analytical methods are reported, such as HPLC with UV detection [7,8], high-throughput HPLC technique [9], Liquid chromatographic method [10], LC and LC/MS approach [1,11], high-throughput LC-ESI-MS [12], HPLC with electrospray tandem mass spectrometry [13] and HPLC technique [14,15]. However, the reported analytical methods measured only solo everolimus using different detectors. Hence, an attempt was made to develop and validate a simple, precise and sensitive, stability indicating reverse-phase HPLC method for the determination of all everolimus impurities (IMP-A, IMP-B, IMP-C, IMP-D, IMP-E, sirolimus and TGR) present in everolimus tablet dosage form.

The present validated analytical method for estimation of everolimus is based on the quality by design $(\mathrm{QbD})$ approach

This is an open access journal, and articles are distributed under the terms of the Creative Commons Attribution-NonCommercial-ShareAlike 4.0 (CC BY-NC-SA 4.0) International License which allows readers to freely read, download, copy, distribute, print, search, or link to the full texts of its articles and to use them for any other lawful non-commercial purpose as long as the original source is duly acknowledged. 
which is build up for the understanding of intended purposes, predictive solutions and following the design of experiments (DOE) approach [16-20]. The analytical method is validated and developed by the guidelines of the International Conference on Harmonization (ICH) Q8, Q9, Q10 and Q11 [21-24]. The IUPAC nomenclature and molecular structures of everolimus and its impurities are presented in Table-1 and Fig. 1, respectively.

\section{EXPERIMENTAL}

High-performance liquid chromatography (HPLC) with a quaternary solvent manager (Agilent/waters, USA) and a UV-visible/PDA detector were used. The Empower-3 software was used for processing and monitoring the output signal. The electronic analytical balance (Thermo Fisher Scientific, Hyderabad, India) was used for weighing purposes. The stan- dard everolimus (purity, $\geq 99.9 \%$ ) and its impurities were obtained from Dr. Reddy's Laboratories Limited, Hyderabad, India and acetonitrile of gradient grade, formic acid, methanol and ammonia were acquired from Merck KGaA (Darmstadt, Germany).

The everolimus stabilized with BHT is packed either in quadruple layered aluminium foil bags or triple covered aluminium foil bags. The active substance of drug is contacted with the polyethylene layer. The bags were sealed in a protective atmosphere which contains the gases of nitrogen or argon to protect the sample from oxidation, light and humidity and placed in the suitable containers during handling.

Chromatographic conditions: Waters HPLC instrument with PDA detector was used for the method development and validation of the samples. A stationary phase C18 (make Zorbax SB C18) column with $250 \mathrm{~mm}$ length, $4.6 \mathrm{~mm}$ internal

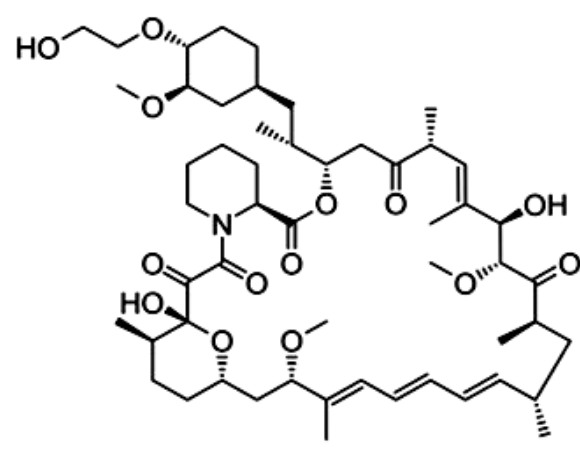

Everolimus

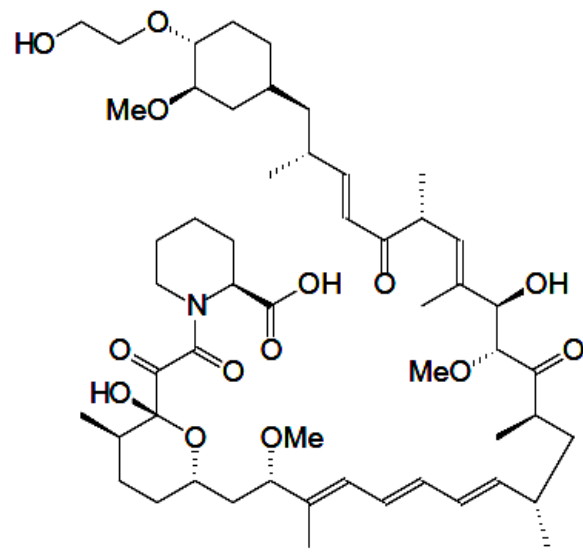

Everolimus impurity-C

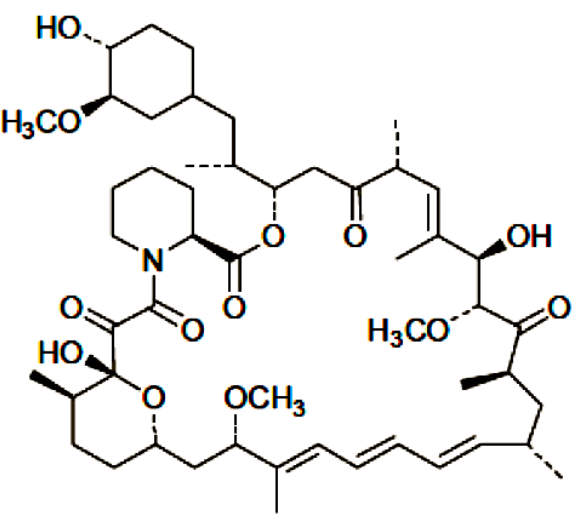

Sirolimus/Rapamycin

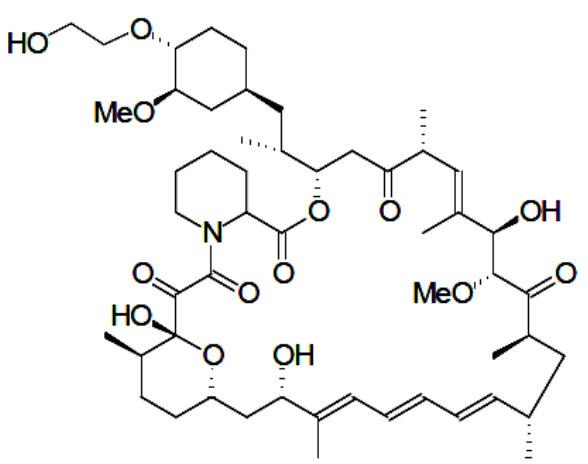

Everolimus impurity-A

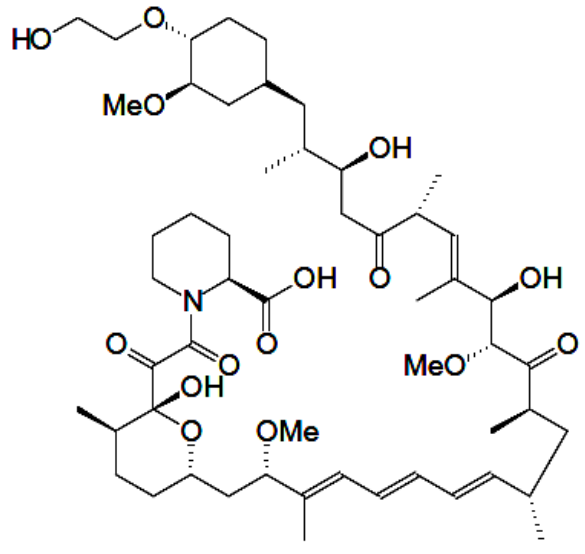

Everolimus impurity-B<smiles></smiles>

Everolimus impurity-D<smiles>COCC(=O)C(C)C/C=C/C=C/C=C(/C)[C@H](CC1CCC(C)[C@](O)(C(=O)C(=O)N2CCCCC2C(=O)O)O1)OC</smiles>

Everolimus impurity-E

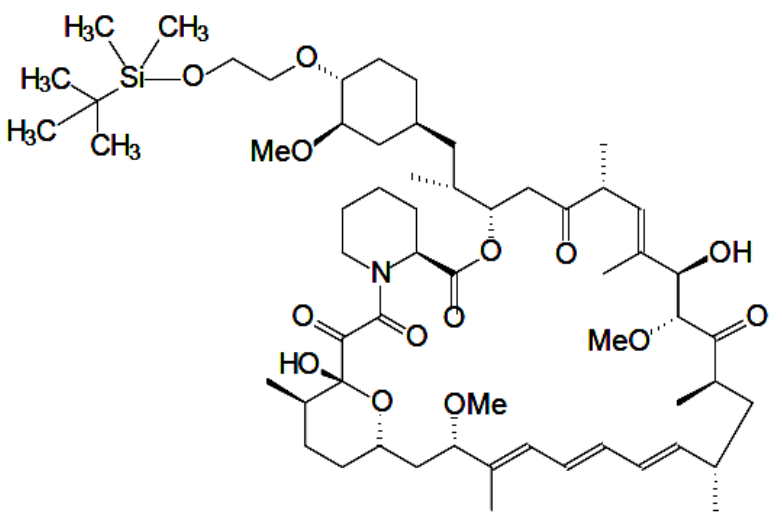

Everolimus TGR impurity

Fig. 1. Molecular structures of everolimus and its all related compounds 


\begin{tabular}{|c|c|}
\hline & $\begin{array}{c}\text { TABLE-1 } \\
\text { IUPAC NOMENCLATURES OF EVEROLIMUS AND ITS IMPURITIES }\end{array}$ \\
\hline Name & IUPAC nomenclatures \\
\hline Everolimus (Isomer-B) & $\begin{array}{l}\text { 1R,9S,12S,15R,16E,18R,19R,21R,23S,24E,26E,28E,30S,32S,35R)-1,18-dihydroxy-12-\{(1R)-2-[(1S,3R,4R)-4-(2- } \\
\text { hydroxyethoxy)-3-methoxycyclohexyl]-1-methylethyl }\}-19,30 \text {-dimethoxy-15,17,21,23,29,35-hexamethyl-11,36- } \\
\text { dioxa-4-aza tricyclo[30.3.1.04,9]hexatriaconta-16,24,26,28-tetraene-2,3,10,14,20-pentaone }\end{array}$ \\
\hline Impurity-A & $\begin{array}{l}\text { Trihydroxy-12-\{(2R)-1-[(1S,3R,4R)-4-(2-hydroxyethoxy)-3-methoxycyclohexyl]propan-2-yl\}-19-methoxy- } \\
\text { 15,17,21,23,29,35-hexamethyl-11,36-dioxa-4-azatricyclo[30.3.1.04,9]hexatriaconta-16,24,26,28-tetraene- } \\
\text { 2,3,10,14,20-pentone }\end{array}$ \\
\hline Impurity-B & $\begin{array}{l}\text { 2-Piperidinecarboxylic acid,1-[2-oxo[(2R,3R,6S)-tetrahydro-2-hydroxy-6-[(2S,3E,5E,7E,9S,11R,13R,14R,15E,17R, } \\
\text { 20S,21R)-14,20-dihydroxy-22-[(1S,3R,4R)-4-(2-hydroxyethoxy)-3-methoxycyclohexyl]-2,13-dimethoxy-3,9,11,15, } \\
\text { 17,21-hexamethyl-12,18-dioxo-3,5,7,15-docosabutaen-1-yl]-3-methyl-2Hpyran-2-yl]acetyl }\end{array}$ \\
\hline Impurity-C & $\begin{array}{l}\text { 2-Piperidinecarboxylic acid,1-[2-oxo[(2R,3R,6S)-tetrahydro-2-hydroxy-6-[(2S,3E,5E,7E,9S,11R,13R,14R,15E,17R, } \\
\text { 19E,21R)-14-hy-droxy-22-[(1S,3R,4R)-4-(2-hydroxyethoxy)-3-methoxycyclohexyl]-2,13-dimethoxy-3,9,11,15,17, } \\
\text { 21-hexamethyl-12,18-dioxo-3,5,7,15,19-docosapentaen-1-yl]-3-methyl-2H-pyran-2-yl]acetyl }\end{array}$ \\
\hline Impurity-D & $\begin{array}{l}\text { (2R,3S,6R,7E)-1-((1S,3R,4R)-4-(2-Hydroxyethoxy)-3-methoxycyclohexyl)-2,6,8-trimethyl-5,9-dioxo-7-ene-3-yl-1- } \\
\text { (2-((2R,3R,6S)-6-((2S,3E,5E,7E,9S,11R)-2,13-dimethoxy-3,9,11-trimethyl-12-oxotrideca-3,5,7-triene-1-yl)-2- } \\
\text { hydroxy-3-methyltetrahydro-2H-pyran-2-yl)-2-oxoacetyl)piperidine-2-carboxylate }\end{array}$ \\
\hline Impurity-E & $\begin{array}{l}\text { 1-(2-((2R,3R,6S)-6-((2S,3E,5E,7E,9S,11R)-2,13-dimethoxy-3,9,11-trimethyl-12-oxotrideca-3,5,7-triene-1-yl)-2- } \\
\text { hydroxy-3-methyltetrahydro-2Hpyran-2-yl)-2-oxoacetyl)piperidine-2-carboxylic acid }\end{array}$ \\
\hline Sirolimus/Rapamycin & $\begin{array}{l}\text { (3S,6R,7E,9R,10R,12R,14S,15E,17E,19E,21S,23S,26R,27R,34AS)-9,10,12,13,14,21,22,23,24,25,26,27,32,33,34, } \\
\text { 34A-hexadecahydro-9,27-dihydroxy-3-((1R)-2-((1S,3R,4R)-4-hydroxy-3-methoxycyclohexyl)-1-methylethyl)- } \\
\text { 10,21-dimethoxy-6,8,12,14,20,26-hexamethyl-23,27-epoxy-3H-pyrido(2,1-C)-(1,4)oxaazacyclohentriacontine- } \\
\text { 1,5,11,28,29-(4H,6H,31H)-pentone }\end{array}$ \\
\hline TGR -impurity & $\begin{array}{l}\text { Dihydroxy-12-[(2R)-1-[(1S,3R,4R)-4-(2-tert-Butyldime thylsilyloxyethoxy)-3-methoxycyclohexyl]propan-2-yl]- } \\
\text { 19,30-dimethoxy-15,17,21,23,29,35-hexamethyl-11,36-dioxa-4-azatricyclo[30.3.1.04,9]hexatriaconta-16,24,26,28- } \\
\text { tetraene-2,3,10,14,20-pentone }\end{array}$ \\
\hline
\end{tabular}

diameter, $5 \mu$ particle size and a gradient flow mode were adopted to separate all impurities. The buffer solution prepared with the combination of formic acid and ammonia solution was used as mobile phase-A and the methanol and acetonitrile in the proportion of 30:70 (v/v) was used as mobile phase-B. The sample cooler and column temperatures were kept at 5 and $50{ }^{\circ} \mathrm{C}$, respectively and run time is as per below gradient programme. The mobile phase was degassed and thoroughly mixed before use and flow rate of the mobile phase was maintained at $1.0 \mathrm{~mL} / \mathrm{min}$. The injection volumes of $50 \mu \mathrm{L}$ were set for both standards and samples and the eluted compounds were monitored at $280 \mathrm{~nm}$.

\section{Preparation of standards and test solutions}

Sirolimus stock solution: Weighed about $30 \mathrm{mg}$ of sirolimus drug and transferred into a $15 \mathrm{~mL}$ of acetonitrile solution exists in $25 \mathrm{~mL}$ volumetric flask, followed by sonication to complete the mixing and diluted to the mark using acetonitrile solution. Hence prepared solution was used as a working/ reference standard solution.

System suitability solution: Weighed accurately $25 \mathrm{mg}$ of everolimus standard working and transferred into a $20 \mathrm{~mL}$ volumetric flask. $1 \mathrm{~mL}$ of sirolimus stock solution and $17 \mathrm{~mL}$ of diluent were added to the flask by sonication and diluted the volume with diluents.

Standard solution of everolimus: Weighed and transferred $25 \mathrm{mg}$ of everolimus into a $100 \mathrm{~mL}$ flask containing 70 $\mathrm{mL}$ of acetonitrile solution and sonicated until the complete mixing of the drug. Further, the flask was kept on the bench top, allows the solution to reach the room temperature and diluted the quantity with acetonitrile solution. Further, accurately pipette out $5 \mathrm{~mL}$ of above everolimus stock solution into a $250 \mathrm{~mL}$ volumetric flask and dilute to the volume with diluents.
Test preparation: The test solution was prepared by; accurately weighed $30 \mathrm{mg}$ of tablet powder was taken into a $25 \mathrm{~mL}$ volumetric flask, add about $17 \mathrm{~mL}$ of diluents to it and then sonicated the flask for 15 min with intermediate shaking. Then, kept the volumetric flask at bench top and stood the solution to reach the room temperature. Then, the diluent was used to make up the volume and mix well. Centrifuge the resulting solution at $4000 \mathrm{rpm}$ for $10 \mathrm{~min}$ and filter the solution with 0.45 micron PVDF membrane filter.

Spiked sample preparation: $30 \mathrm{mg}$ of everolimus tablet powder was weighed accurately and transferred to a $25 \mathrm{~mL}$ volumetric flask. To get $0.5 \%$ of the test concentration, stock impurity solution was added to the flask, followed by addition of $14 \mathrm{~mL}$ of the diluent. Thus obtained mixture was sonicated until the complete digestion of the drug and then make up to volume with the diluent. Further, the resulting solution was centrifuged at $4000 \mathrm{rpm}$ for $15 \mathrm{~min}$ and $0.45 \mu$ membrane filter was used for filter the solution.

Specificity: The everolimus and its impurities were injected into the optimized system to demonstrate the specificity of the developed method [22]. For the effectual separation of known impurities and degradants of everolimus peak by forced degradation studies, the samples were subjected to different stress conditions like acid $(1.0 \mathrm{~N} \mathrm{HCl})$, base $(0.1 \mathrm{~N} \mathrm{NaOH})$, oxidation $\left(30 \% \mathrm{H}_{2} \mathrm{O}_{2}\right)$, thermal $\left(105^{\circ} \mathrm{C}\right.$ in hot air oven $)$, water conditions ( $3 \mathrm{~mL} / 3$ days bench top), sunlight (1.2 million lux hrs), humidity (90\% RH) and UV light (200 watt-hours).

\section{RESULTS AND DISCUSSION}

Optimization of chromatographic conditions: To acquire the optimum resolution between everolimus and its impurities, mobile phases like ammonium salts, phosphate, sodium perchlorate, formic acid buffers and columns with different manu- 
facturers were taken at different trials. Based on the design of experiments (DOE), the absolute chromatographic conditions were optimized. In the view of $\mathrm{pH}$ of the buffer, flow rate, resolution between the close eluting impurities (sirolimus and everolimus) as response and percentage of acetonitrile in mobile phase-B as factors, DOE was performed using fractional design. For the valuation study, 10 combinations of the factors were used and the text plan was shown in Table- 2 .

\begin{tabular}{ll}
\multicolumn{1}{c}{$\begin{array}{c}\text { TABLE-2 } \\
\text { CONDITIONS OF HPLC METHOD }\end{array}$} \\
\hline Column & $250 \mathrm{~mm} \times 4.6 \mathrm{~mm}, 5 \mu \mathrm{m}$, Zorbax SB C18 \\
Column temp. & $50{ }^{\circ} \mathrm{C}$ \\
Sample cooler temp. & $5{ }^{\circ} \mathrm{C}$ \\
Wavelength & $280 \mathrm{~nm}$ \\
Injection volume & $10 \mu \mathrm{L}$ \\
Run time & $100 \mathrm{~min}$ \\
Gradient & $28 \% \mathrm{~A}$ and $72 \% \mathrm{~B}$ upto 60 min (isocratic) \\
& with $1.0 \mathrm{~mL}$ \\
& Linear gradient to $15 \%$ A at 70 min with \\
& $1.0 \mathrm{~mL}$ \\
& Linear gradient to $8 \% \mathrm{~A}$ at 80 min with 1.0 \\
& $\mathrm{~mL}$ \\
& $8 \% \mathrm{~A}$ and $92 \% \mathrm{~B}$ upto 90 min (isocratic) \\
& with $1.0 \mathrm{~mL}$ \\
& Linear gradient to $28 \%$ A at 90.1 min with \\
& $1.0 \mathrm{~mL}$ \\
& $28 \%$ A and $72 \%$ B upto 100 min \\
& (isocratic) with $1.0 \mathrm{~mL}$ \\
\hline
\end{tabular}

Design of experiments (DOE): The capability of a chromatographic method for successful separation, identification and impurities quantization, which are in the control of the experimenter, were resolute by many factors. The DOE gives a powerful suite for a statistical methodology, which can estimate the effects of each factor alone and as well as in combination. The column temperature and the percentage of acetonitrile in mobile phase-B were identified as critical method parameters
(CMP) for design of experiments (DOE) to estimate the gruffness of the system. The results are presented in Table-3.

Minitab software was used for evaluation of factors effects on resolutions, generating Pareto chart with three-dimensional plots and modeling of transcribed obtained results. Percentage of acetonitrile and flow rate plays a main role in impurities separation. Experimentally proposed values were nearer to the suggested parameters and the design space was established. Moreover, for setting the upper and lower bounds for each variable, experimental data was used. Interactive effects were performed from various overlay graphs plotted between two parameters at a time using visual inspections and modeled data. The results are presented in Figs. 2-5.

Based on the recovery and shape of the peak, the diluents were finalized and test concentrations and injection volumes were optimized to contain greater reporting threshold than the limit of quantification (LOQ). The obtained chromatograms are presented in Figs. 6-10.

\section{Method validations}

System suitability: The $0.4 \%$ standard level of the test solution was prepared and introduced into HPLC system. The percentage of relative standard deviation (RSD) was calculated for peak areas, tailing factors of everolimus peak and USP plate count. The repeated injection of RSD percentage was observed as $0.9 \%$. The plate count and main analyte tailing factor are found to be 8822 and 1.0, respectively and the resolution between sirolimus and everolimus was found to be 2.6. The findings are given in Table- 4 .

Solution stability: The stability of the everolimus and its impurities (IMP-A, IMP-B, IMP-C, IMP-D, IMP-E, sirolimus and TGR) in the spiked sample was examined on the benchtop at room temperature for $24 \mathrm{~h}$. Percentages of impurities and system suitability parameters were evaluated aligned with a fresh standard. All the spiked samples were kept in the air-

TABLE-3

CMP, CQA AND QTMP EVEROLIMUS RELATED SUBSTANCE STABILITY-INDICATING ANALYSIS METHOD

\begin{tabular}{|c|c|c|c|c|c|}
\hline \multirow{2}{*}{ CMP (critical method parameter) } & \multicolumn{3}{|c|}{ Range of each parameters used for DOE } & \multirow{2}{*}{$\begin{array}{c}\text { QTMP (quality target method profile) } \\
\text { Targeted QTMP }\end{array}$} & \multirow{2}{*}{$\begin{array}{l}\text { Critical quality } \\
\text { attribute (CQA) }\end{array}$} \\
\hline & Low & As such & High & & \\
\hline A) Flow rate $(\mathrm{mL} / \mathrm{min})$ & 0.8 & 1.0 & 1.2 & \multirow{4}{*}{$\begin{array}{l}\text { Resolution between serolimus and } \\
\text { everolimus not less than-1.5 }\end{array}$} & \multirow{4}{*}{$\begin{array}{l}\text { Resolution } \\
\text { between } \\
\text { serolimus and } \\
\text { everolimus }\end{array}$} \\
\hline B) $\mathrm{pH}$ of mobile phase-A & 4.1 & 4.3 & 4.5 & & \\
\hline C) $\%$ of acetonitrile in mobile phase-B & 27 & 30 & 33 & & \\
\hline D) Column oven temperature $\left({ }^{\circ} \mathrm{C}\right)$ & 45 & 50 & 55 & & \\
\hline
\end{tabular}

\section{Fitted Means}

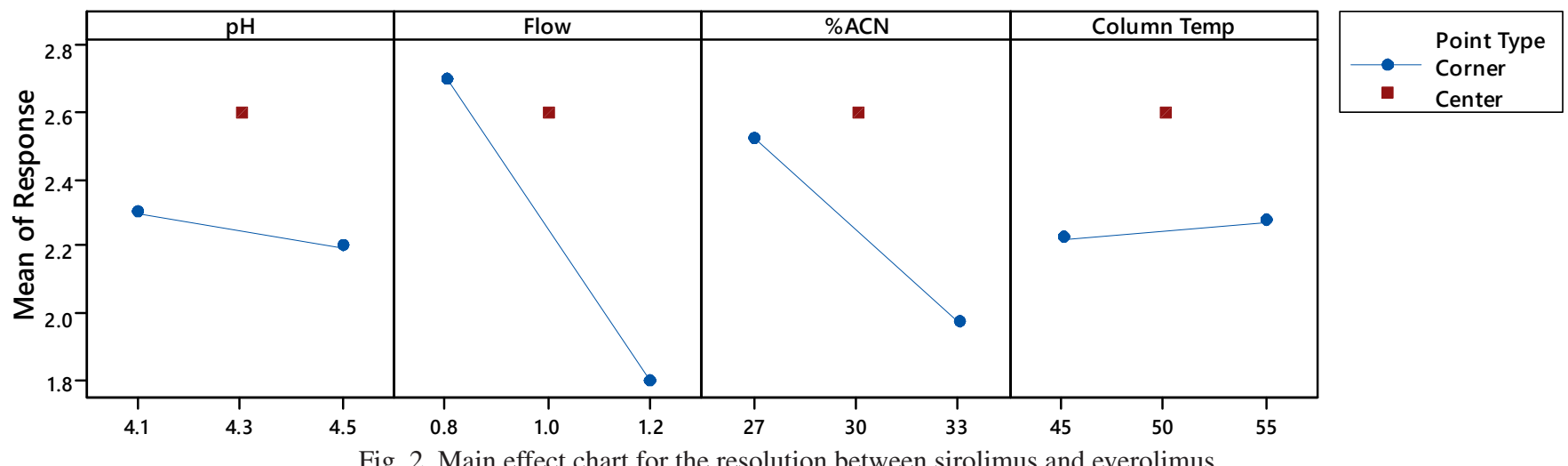

Fig. 2. Main effect chart for the resolution between sirolimus and everolimus 


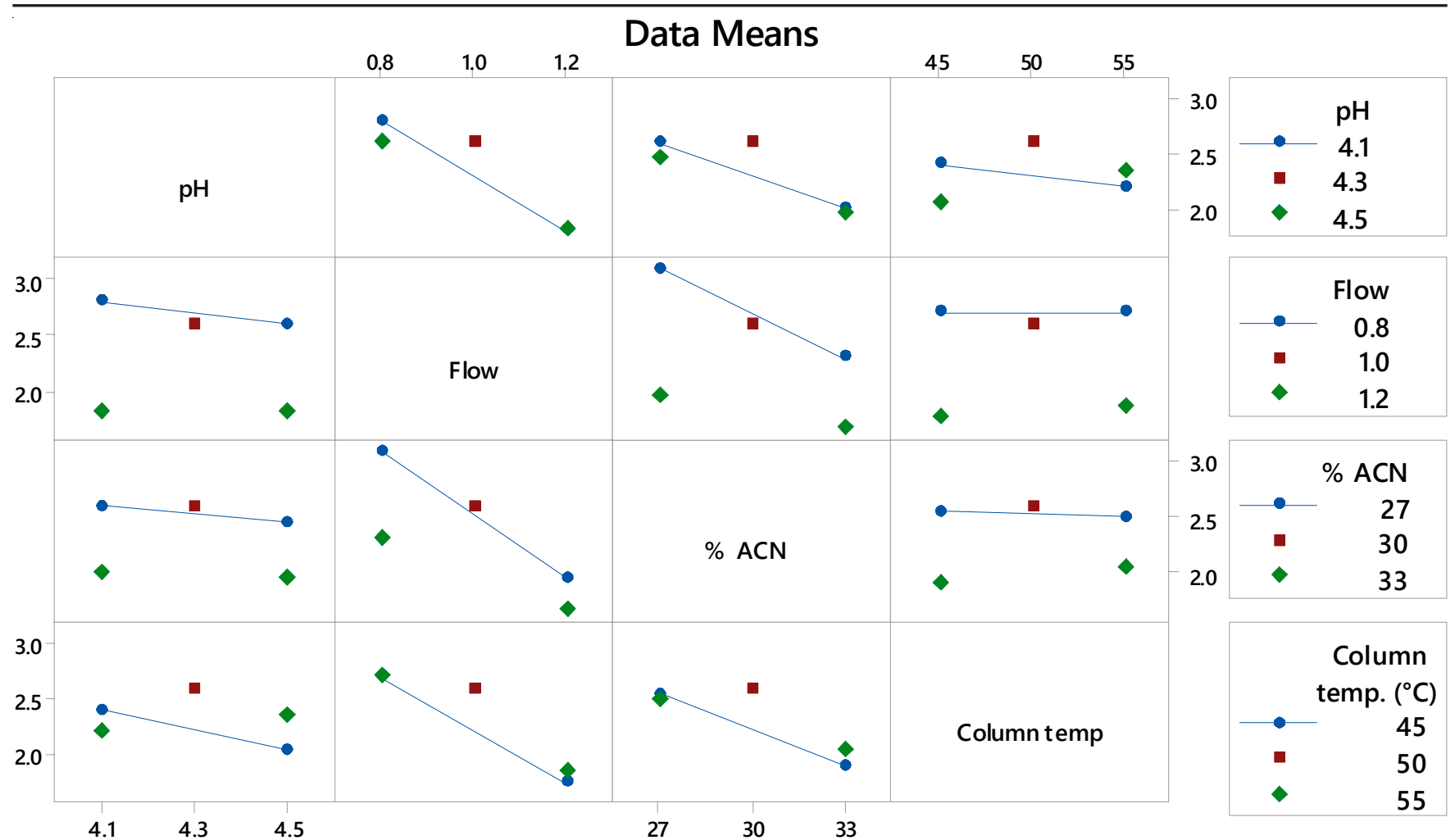

Fig. 3. Interaction plot for the resolution between sirolimus and everolimus

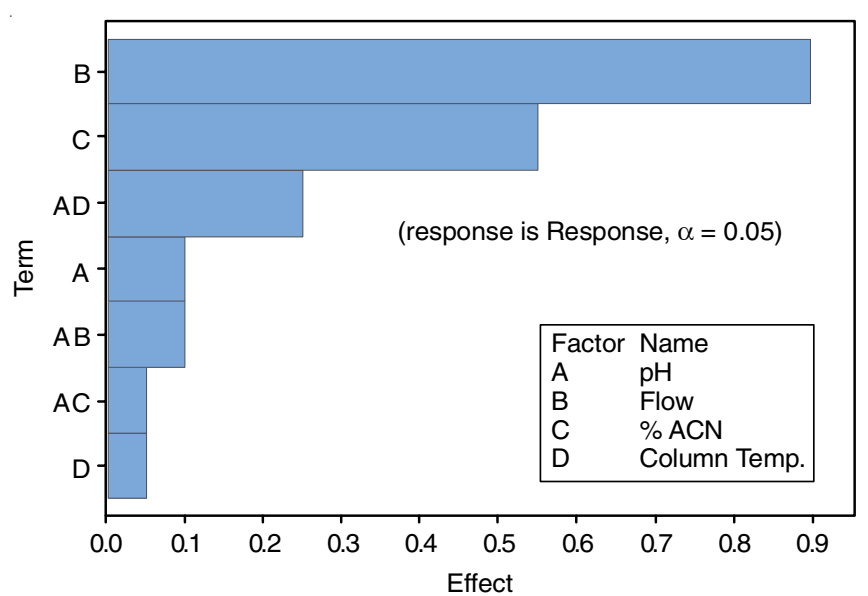

Fig. 4. Pareto chart for standardized effects on the resolution between sirolimus and everolimus

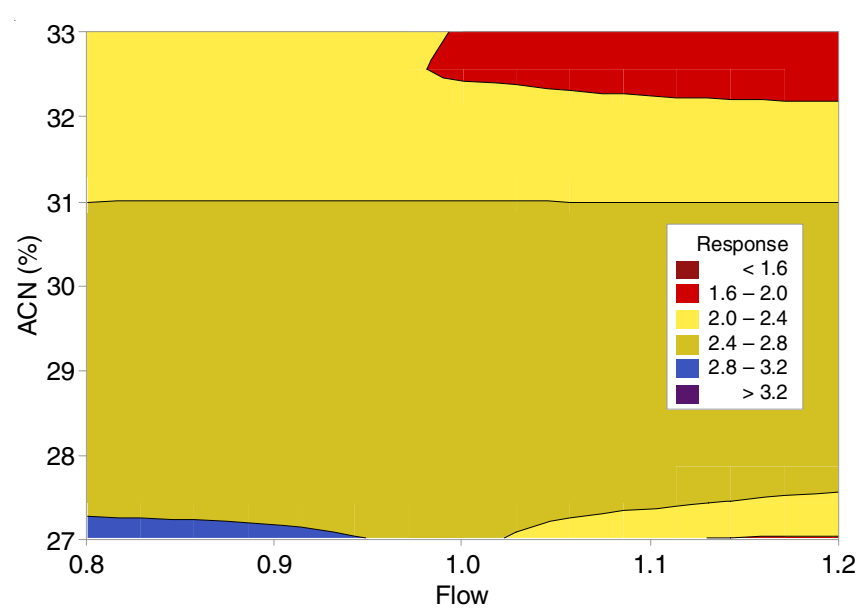

Fig. 5. Contour plot for the resolution between sirolimus and everolimus

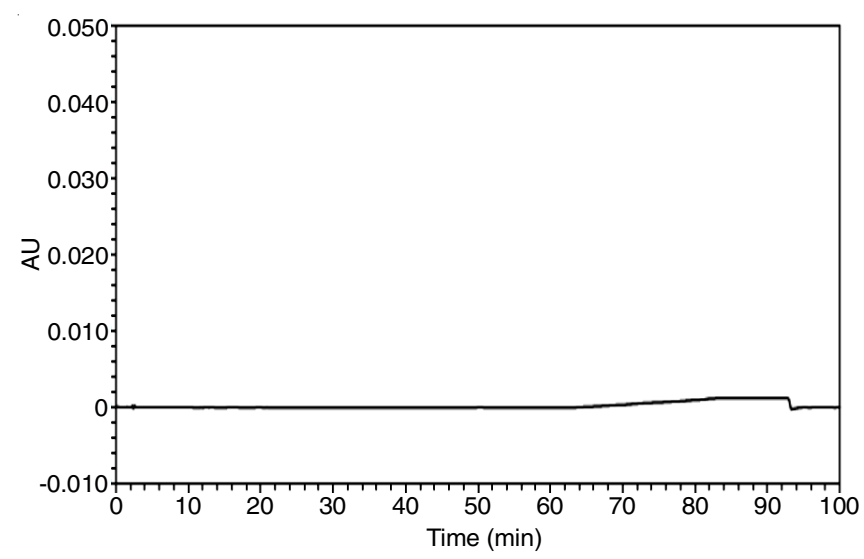

Fig. 6. Chromatogram for blank preparation

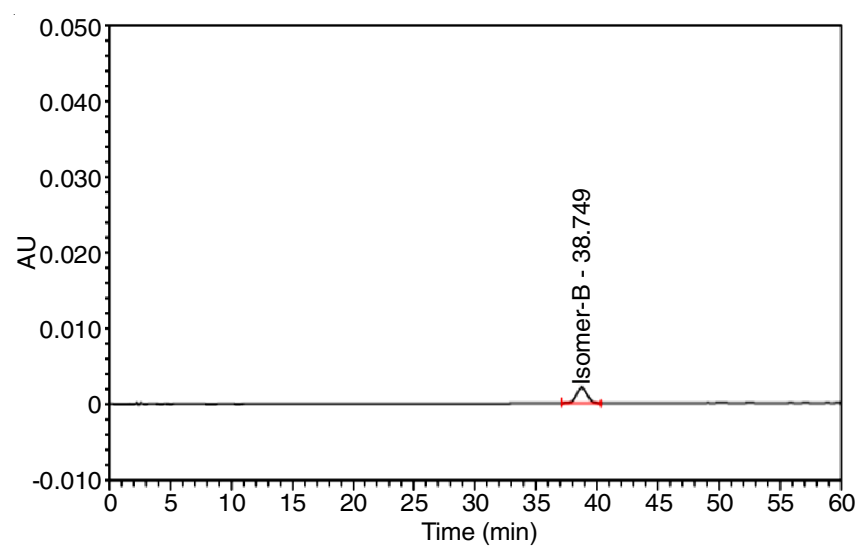

Fig. 7. Chromatogram for standard preparation

tight flasks and found that the mobile phase and solutions are steady up to $24 \mathrm{~h}$. 


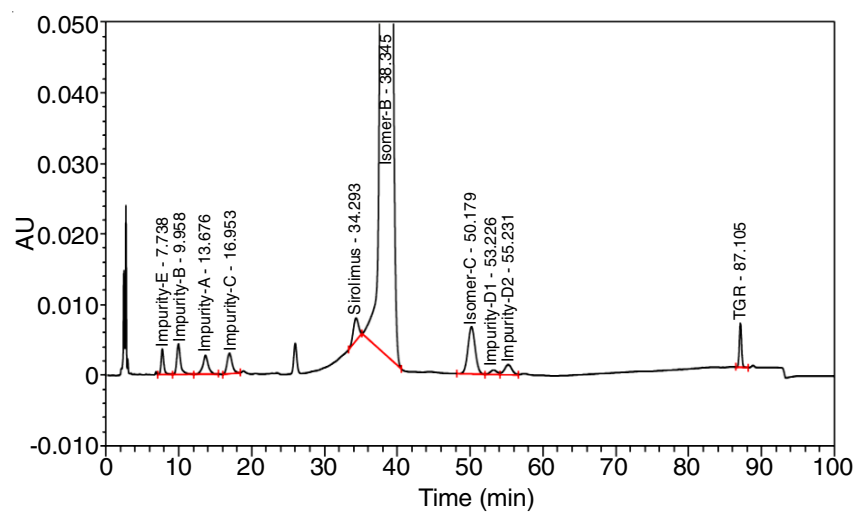

Fig. 8. Chromatogram for spiked sample preparation

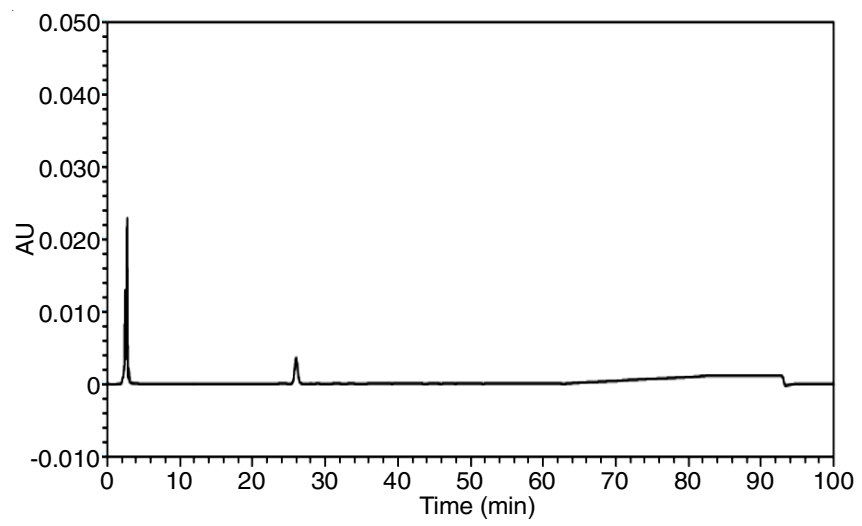

Fig. 9. Chromatogram for placebo preparation

Specificity: The samples were subjected to various stress circumstances like acidic ( $1.0 \mathrm{~N} \mathrm{HCl} / 3 \mathrm{~mL} / 15 \mathrm{~min}$ bench top), alkaline $(0.1 \mathrm{~N} \mathrm{NaOH} / 3 \mathrm{~mL} / 45 \mathrm{~s}$ bench top), oxidation (\% 30 $\mathrm{H}_{2} \mathrm{O}_{2} / 3 \mathrm{~mL} / 2$ days bench top), thermal $\left(80{ }^{\circ} \mathrm{C} / 72 \mathrm{~h}\right)$, water conditions ( $3 \mathrm{~mL} / 3$ days bench top), sunlight (1.2 million lux hours), humidity (90\% RH for 3 days) and UV light (200 watt hours). All the samples were subjected to HPLC system with a PDA detector to find the known and unknown peaks and purity of the main analyte. For all the everolimus and its

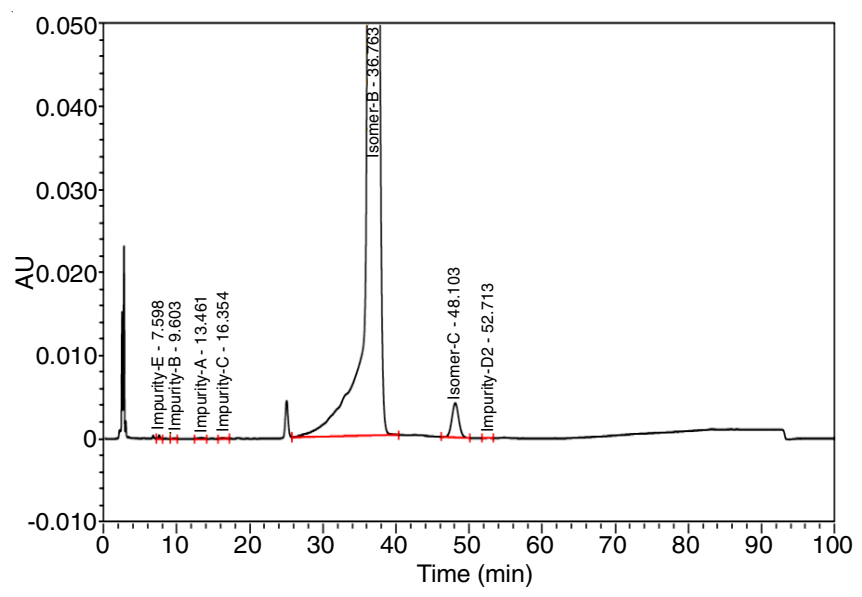

Fig. 10. Chromatogram for sample preparation

known impurities peaks, purity angles are fewer than the purity threshold. The degradation products of everolimus were effectively separated by the developed method. Hence, the method is considered to be extremely selective and specific for future use. The findings are presented in Table-5.

Range and linearity: The linearity was examined above the series of 0.9 to $9.0 \mathrm{mg} / \mathrm{L}$ for the main analyte and all impurities (IMP-A, IMP-B, IMP-C, IMP-D, IMP-E, sirolimus and TGR). The prepared six dissimilar linearity solutions were injected into the HPLC system and the findings are presented in Table-6.

LOD and LOQ: To examine the LOD and LOQ, dissimilar concentrations of solutions were prepared by spiking known amounts of impurities and spiked everolimus in the diluent. The slope method was used for estimation of LOD and LOQ and the equations used are $\mathrm{LOQ}=10 \times \sigma / \mathrm{S}$ and $\mathrm{LOD}=3.3 \times$ $\sigma / \mathrm{S}$, where, $\mathrm{S}$ is the calibration curve slope and $\sigma$ is the standard deviation of the response. LOQ values of 0.08-0.1 were found. Detection limits and quantitation limits were determined by the signal-to-noise $(\mathrm{S} / \mathrm{N})$ approach and the concentration ratio with a signal to the noise about ten was taken as LOQ and three was taken as LOD. The results were presented in Table-6.

\begin{tabular}{lcc} 
& \multicolumn{2}{c}{ TABLE-4 } \\
& \multicolumn{1}{c}{ SYSTEM SUITABILITY PARAMETERS } & Acceptance criteria \\
\hline \multicolumn{1}{c}{ System suitability parameters } & Observation & Not more than 1.5 \\
\hline Tailing factor for everolimus peak in diluted standard preparation & 1.0 & Not less than 1500 \\
Plate count for everolimus peak & 8822 & Not more than 10 \\
\% RSD for areas of everolimus & 0.9 & Not less than 1.5 \\
Resolution between sirolimus and everolimus & 2.6 & \\
\hline
\end{tabular}

TABLE-5

SUMMARY OF PEAK PURITY AND DEGRADATION DATA FOR EVEROLIMUS IN STRESS STUDY

\begin{tabular}{|c|c|c|c|c|c|}
\hline Stress condition & $\begin{array}{c}\% \text { Net } \\
\text { degradation }\end{array}$ & $\begin{array}{l}\text { Purity } \\
\text { angle }\end{array}$ & $\begin{array}{c}\text { Purity } \\
\text { threshold }\end{array}$ & Purity flag & $\begin{array}{l}\text { (\%) Mass } \\
\text { balance }\end{array}$ \\
\hline Unstressed sample & NA & 0.105 & 0.428 & NO & NA \\
\hline Stressed with $1.0 \mathrm{~N} \mathrm{HCl}$ solution at bench top for $15 \mathrm{~min}$ & 2.1389 & 0.086 & 0.474 & NO & 95 \\
\hline Stressed with $0.1 \mathrm{~N} \mathrm{NaOH}$ solution at bench top for $45 \mathrm{~s}$ & 17.7907 & 0.183 & 0.515 & NO & 97 \\
\hline Stressed with water at 3 days bench top & 10.7936 & 0.195 & 0.496 & NO & 95 \\
\hline Stressed with $30 \% \mathrm{H}_{2} \mathrm{O}_{2} 2$ days at room temperature under dark control & 16.4539 & 0.242 & 0.506 & NO & 104 \\
\hline Heated at $80^{\circ} \mathrm{C}$ for about 3 days & 1.025 & 0.132 & 0.373 & NO & 101 \\
\hline Humidity: 3 days at $90 \% \mathrm{RH}$ & 1.1979 & 0.142 & 0.400 & NO & 100 \\
\hline $\begin{array}{l}\text { Exposed to visible light for about } 1.2 \text { Million Lux-hours and UV light for } \\
\text { about } 200 \text { Watt-hours/meter square }\end{array}$ & 3.9636 & 0.130 & 0.365 & NO & 95 \\
\hline
\end{tabular}


TABLE-6

THE OBTAINED LOQ, LOD, PRECISION AND ACCURACY VALUES

\begin{tabular}{ccccccccc}
\hline Parameters & Imp-A & Imp-B & Imp-C & Imp-D & Imp-E & Sirolimus & TGR \\
\hline LOQ (\%) & 0.08 & 0.08 & 0.10 & 0.10 & 0.10 & 0.08 & 0.08 \\
LOD (\%) & 0.05 & 0.05 & 0.07 & 0.07 & 0.07 & 0.05 & 0.05 \\
Precision & $108.4-109.8$ & $102.6-104.0$ & $95.0-96.8$ & $107.7-109.3$ & $99.6-104.8$ & $95.0-98.0$ & $108.0-109.8$ \\
\hline \multicolumn{7}{c}{ Accuracy } \\
\hline LOQ & $106.7-108.9$ & $98.7-106.1$ & $92.6-99.7$ & $102.7-109.8$ & $98.9-105.9$ & $95.9-99.8$ & $105.7-108.9$ \\
$50 \%$ & 106.7 & 105.1 & 89.7 & 110.0 & 91.7 & 92.3 & 109.9 \\
$100 \%$ & 105.7 & 103.0 & 92.9 & 105.4 & 98.6 & 97.2 & 108.0 \\
$150 \%$ & 104.9 & 98.5 & 88.4 & 107.4 & 91.5 & 95.7 & 106.6 \\
\hline
\end{tabular}

Accuracy and precision: The inter-day and intra-day output data are presented in Table-6. Six samples were prepared at $0.5 \%$ of the targeted test solution by spiking the impurities. Recovery studies from 0.9 to $9.0 \mathrm{mg} / \mathrm{L}$ were performed for all the impurities and the values were obtained between $85-110 \%$. The accuracy was calculated as \% bias (divergence between measured concentrations and nominal concentrations) and precision was calculated within a single run (intra-day) and different runs (inter-day). The ensuing percentage of relative standard deviation (RSD) values of everolimus impurities were observed below $5.0(\mathrm{n}=6)$. Therefore, the method is precise and accurate.

\section{Conclusion}

A novel quality by design (QbD) based reversed-phase HPLC method was developed and validated for the determination of everolimus and its degradation products. The method is validated in conditions of linearity, recovery and specificity. All the compounds are monitored with the detector photodiode array (PDA) at $280 \mathrm{~nm}$ and a stable bond stationary phase containing $250 \mathrm{~mm} \times 4.6 \mathrm{~mm}, 5 \mu \mathrm{m}$, Zorbax SB C18 column is developed. The critical method parameters are found and applied to DOE, which shows the abruptness of the chromatographic method before validation. Recovery studies from 0.9 to $9.0 \mathrm{mg} / \mathrm{L}$ are performed for all impurities and the values were obtained between $85-110 \%$. The flow gradient has been optimized and the developed method is found to be vigorous within the distinct design space. The validated method was verified to be selective, precise, accurate robust and have good LOD and LOQ values. Everolimus and all generated unknown impurities in the degradation are well separated and the present developed method is helpful in the regions where regulatory agencies recommend HPLC analytical methods.

\section{ACKNOWLEDGEMENTS}

The authors thank the management of Dr. Reddy's Laboratories Ltd. for their valuable support to carry out this research work.

\section{CONFLICT OF INTEREST}

The authors declare that there is no conflict of interests regarding the publication of this article.

\section{REFERENCES}

1. P. Morgan, M. Nwafor and M. Tredger, Biomed. Chromatogr, 30, 983 (2016);

https://doi.org/10.1002/bmc.3628.

2. A.T. Phan and B. Dave, Cancer Med., 5, 2953 (2016);

https://doi.org/10.1002/cam4.742.
3. Certican (Everolimus), Summary of Product Characteristics, European Medicines Agency (2013).

4. D.M. Parkin, F. Bray, J. Ferlay and P. Pisani, Int. J. Cancer, 94, 153 (2001); https://doi.org/10.1002/ijc.1440.

5. A.O. Ferreiro, M.A. Vazquez-Millán, F.S. López, M.G. Gutiérrez, S.P. Diaz and M.J.L. Patiño, Transplant. Proceed., 46, 3496 (2014); https://doi.org/10.1016/j.transproceed.2014.08.045.

6. L.B. Jeng, A. Thorat, Y.W. Hsieh, H.R. Yang, C.C. Yeh, T.H. Chen, S.C. Hsu and C.H. Hsu, Transplant. Proceed., 46, 744 (2014); https://doi.org/10.1016/j.transproceed.2013.11.068.

7. D.C. French, M. Saltzgueber, D.R. Hicks, A.L. Cowper and D.W. Holt, Clin. Chem., 47, 1316 (2001).

8. K. Marika, F. Katherine, L. Jianmin, C.G. Mike and F. Debra, J. Chromatogr. Sci., 46, 23 (2008);

https://doi.org/10.1093/chromsci/46.1.23.

9. D.W. Holt, T. Lee and A. Johnston, Clin. Ther., 22, B38 (2000); https://doi.org/10.1016/S0149-2918(00)89021-9.

10. R.N. Rao, P.K. Maurya, M. Ramesh, R. Srinivas and S.B. Agwane, Biomed. Chromatogr., 24, 1356 (2010); https://doi.org/10.1002/bmc.1450.

11. A. Kumar and J. Vidyasagar, J. Pharm. Res., 8, 152 (2014).

12. N. Mochizuki, E. Suka, K. Matsumoto, O. Akimoto, T. Shimamura, K. Ohno, H. Furukawa, S. Todo and S. Kishino, Biomed. Chromatogr, 23, 267 (2009);

https://doi.org/10.1002/bmc.1109.

13. P. Salm, P.J. Taylor, S.V. Lynch and P.I. Pillans, J. Chromatogr. B Analyt. Technol. Biomed. Life Sci., 772, 283 (2002);

https://doi.org/10.1016/S1570-0232(02)00107-1.

14. B. Sharmila, A.L. Rao and L. Kalyani, Indian J. Pharm. Sci., 77, 599 (2015); https://doi.org/10.4103/0250-474X.169044

15. S. Maleki, S. Graves, S. Becker, R. Horwatt, D. Hicks, R.M. Stroshane and H. Kincaid, Clin. Ther, 22, B25 (2000); https://doi.org/10.1016/S0149-2918(00)89020-7.

16. S. Karmarkar, R. Garber, Y. Genchanok, S. George, X. Yang and R. Hammond, J. Chromatogr. Sci., 49, 439 (2011); https://doi.org/10.1093/chrsci/49.6.439.

17. K. Monks, I. Molnar, H.J. Rieger, B. Bogati and E. Szabo, J. Chromatogr. A, 1232, 218 (2012); https://doi.org/10.1016/j.chroma.2011.12.041.

18. G.L. Reid, G. Cheng, D.T. Fortin, J.H. Harwood, J.E. Morgado, J. Wang and G. Xue, J. Liq. Chromatogr. Relat. Technol., 36, 2612 (2013); https://doi.org/10.1080/10826076.2013.765457.

19. K.E. Monks, H.J. Rieger and I. Molnar, J. Pharm. Biomed. Anal., 56, 874 (2011); https://doi.org/10.1016/j.jpba.2011.04.015.

20. S. Orlandini, S. Pinzauti and S. Furlanetto, Anal. Bioanal. Chem., 405, 443 (2013); https://doi.org/10.1007/s00216-012-6302-2.

21. ICH, Guideline Q8 (R2), Pharmaceutical Development International Conference on Harmonisation, International Conference on Harmonization Tripartite Guideline (2005).

22. ICH, Guideline Q9, Quality Risk Management International Conference on Harmonization Tripartite Guideline (2005).

23. ICH, Guideline Q10, Pharmaceutical Quality System, International Conference on Harmonization Tripartite Guideline (2007).

24. ICH, Guideline Q11, Pharmaceutical Quality System, International Conference on Harmonization Tripartite Guideline (2012) 